\title{
Globalisation and Food Consumption in Tourism *
}

\author{
Athena H.N. Mak, University of Surrey, UK \\ Margaret Lumbers, University of Surrey, UK \\ Anita Eves, University of Surrey, UK
}

* This is a draft version of the paper. For the published version, please consult the journal website: http://www.sciencedirect.com/science/article/pii/S0160738311000946

\begin{abstract}
In this paper, the common perception of globalisation as a threat to local gastronomic identities is contrasted by its other facet, as an impetus that opens up new opportunities for reinvention of local gastronomic products and identities. Relevant perspectives and theories of globalisation are reviewed to provide a theoretical framework for the study. Key dimensions underlying food consumption in tourism are elucidated, and the impacts of globalisation on the culinary supply and tourist food consumption are discussed. A conceptual model is developed in an attempt to illustrate the influence of globalisation on food consumption in tourism. This study concludes that from the world culture theory perspective, globalisation can be an impetus to reconstruct or reinvent local gastronomic traditions and particularities.
\end{abstract}

Keywords: world culture theory; theory of glocalisation; localisation; local culinary supply; food consumption in tourism; convergence and divergence.

\section{INTRODUCTION}

Food consumption in the general context is recognised as a collection of contextual and evolving social practices, where food no longer merely serves as sustenance but also a way to relate to other people in social, cultural and political terms (Oosterveer, 2006). In the context of tourism, food consumption is likewise acknowledged to bear 'symbolic' significance; for example, as a marker of social distinction (Chang, Kivela, \& Mak, 2010; Kim, Eves, \& Scarles, 2009), and a way for encountering and experiencing other foodways and cultures (Chang, et al., 2010; Molz, 2007). On the other hand, food provides energy and essential nutrients needed for body functions, and thus, eating is at the same time regarded as an 'obligatory' tourist activity (Richards, 2002). Furthermore, eating is an unique form of 
touristic activity that gratifies all five senses - vision, tactile, auditory, taste, and olfaction (Kivela \& Crotts, 2006), offering tourists 'sensory pleasure' that can fulfil the 'experiential' part of the tourist experience (Hjalager \& Richards, 2002).

The significant implications of tourist food consumption on destinations have received a growing research interest recently. Evidence from a number of studies suggests that tourists' interests in and preferences for food in a destination can play a significant role in affecting their destination choice (Bessiere, 1998; Cohen \& Avieli, 2004; Hall \& Mitchell, 2001; Hall \& Sharples, 2003; Hjalager \& Richards, 2002; Long, 2004). Tourists' spending on food can constitute up to one-third of the total tourist expenditure (Hall \& Sharples, 2003; Telfer \& Wall, 2000), thus comprising a significant proportion of tourism revenue. Tourists' food choice and preferences are recognised as important forces driving the tourism demand for food, which have an immediate influence on the offerings of tourist-oriented hospitality businesses and a significant impact on local food supply; for instance, with regard to the amount of food imported for tourists, the linkage between local agriculture production and tourism, and the use of provenance as a distinctive attribute of local food products to attract tourists' attention (Morgan, Marsden, \& Murdoch, 2006; Telfer \& Wall, 2000; Torres, 2002, 2003).

Despite the importance of food consumption in the context of tourism, little is known about the phenomenon in general, and from the sociological perspective in particular (Cohen \& Avieli, 2004). Whilst the ongoing process of globalisation has brought about profound transformations in food production and consumption (Oosterveer, 2006; Wilhelmina, et al., 2010), a number of studies suggest that food consumption in tourism is also subject to the macro influences of globalisation (Hall \& Mitchell, 2002a; Richards, 2002; Symons, 1993; Torres, 2002). For instance, there is a concern that cultural imperialism (Tomlinson, 1991) and McDonaldisation (Ritzer, 1995) may lead to homogenisation that can result in a 'global palate' as well as a 'global cuisine' (Richards, 2002; Ritzer, 1995; Symons, 1993). The homogenising force of globalisation is thus commonly seen as a threat to the close connection between food and place, or as Trubek (2008) puts it, the 'taste of place' or 'terroir'. Hence, globalisation can significantly affect local gastronomic identity and image (the holistic impression of the gastronomic landscape of a destination) (Fox, 2007; Harrington, 2005), and can result in the deprivation of a 'sense of place' for both locals and tourists (Richards, 2002). Such an outcome would be most threatening to destinations that utilise their local cuisine and gastronomic products as a source of tourist attraction or as a major image differentiator from 
their competitors.

Whilst it is a common perception that globalisation poses a threat to local gastronomic identity and image, there is preliminary evidence suggesting that it can provide an impetus for reinventing local gastronomic products and identity. Torres (2002) contends that the 'average world citizen' now has increased exposure to a wider variety of ethnic dishes and products, thus this trend may stimulate a greater demand for local speciality products and indigenous cuisines. Ram (2004) also found that McDonaldisation in Israel did not bring about the demise of local delicacies, but instead contributed to their revival. Accordingly, it is not only necessary to examine food consumption in tourism, but also to consider the interplay between globalisation and food in tourism. Such knowledge will be crucial to destination marketers in devising effective strategies for marketing and positioning their gastronomic products as well as in providing theoretical groundwork for further research into food in tourism, an important area which has been neglected in the past (Chang, et al., 2010; Cohen \& Avieli, 2004). It is in such a context that this paper explores the influence of globalisation on food consumption in tourism. Specifically, relevant perspectives and theories of globalisation are examined in order to provide a theoretical framework for the study. Various perspectives of tourist food consumption research are reviewed to identify the key dimensions underlying food consumption in tourism. Then, the paper discusses the impacts of globalisation on local culinary supply and tourist food demand. In conclusion, a conceptual model is developed to illustrate globalisation's influence on food consumption in tourism. It should be noted that whilst local culinary supply may include production, processing, wholesaling, retailing, and food services, the focus of this paper is predominantly on the food service sector as it is one of the most important value adding sectors in the context of tourism (Smith \& Xiao, 2008).

\section{GLOBALISATION AND FOOD CONSUMPTION IN TOURISM}

\section{Globalisation: Perspectives and Dimensions}

Globalisation has influenced many aspects of human activity, including food production and consumption (Lang, 1999; Wilhelmina, et al., 2010). Although it is not a new phenomenon, the speed and scope of change are accelerating, mostly facilitated by the unprecedented advances in transport, information and communication technology (Lang, 1999; Reiser, 2003). Nonetheless, giving a unified definition of globalisation is difficult and problematic because the ideas behind the concept are varied, and its history and consequences 
are seen from different viewpoints. Giddens (1990, p. 64) refers to globalisation as 'the intensification of worldwide social relations, which link distant localities in such a way that local happenings are shaped by events occurring many miles away and vice versa'. Robertson (1992, p. 8) defines globalisation as 'the compression of the world and the intensification of consciousness of the world as a whole'. Waters (2001, p. 5) delineates globalisation as 'a social process in which the constraints of geography on economic, political, social and cultural arrangements recede, in which people become increasingly aware that they are receding, and in which people act accordingly'. These definitions emphasise that globalisation brings about an intensified worldwide interdependence and integration as well as an increased global consciousness.

Jenkins (2004, p. 1) cites that globalisation is 'a process of greater integration within the world economy through movements of goods and services, capital, technology and (to a lesser extent) labour'. This emphasis on 'movement' corresponds with the fundamental concept of tourism, which involves the movement of people, goods, services, ideas, and money over space (Schmelzkopf, 2002). Indeed, human mobility, which includes movements associated with migration, immigration and tourism, has significant impact on globalisation of food (Inglis \& Gimlin, 2009). Accordingly, the concept of globalisation is highly relevant for studies of food in the context of tourism. Reiser (2003, p. 309) suggests that the term 'globalisation' denotes the plurality of the concept, as there are several kinds of globalisation such as economic, political, cultural, and environmental, and that 'these globalisations are impacting on tourism just as tourism is impacting upon globalisations'. Inglis and Gimlin (2009, p. 4) similarly emphasise that it is more appropriate to refer to 'globalisations of food' in the plural sense, for there is 'no singular, unequivocal globalisation process, but rather there exist multifarious globalisation processes in the plural'.

From the sociological viewpoint, there are four major perspectives of globalisation: world-system theory, neorealism/neoliberal institutionalism, world-polity theory, and world culture theory (Lechner \& Boli, 2003). World culture theory is a relatively new perspective in understanding the key dimensions and consequences of globalisation. The theory interprets globalisation as a process in which its participants become conscious of and give meaning to living in the world as a single entity under a 'hybrid' world culture (Robertson, 1992). Hence, the world culture perspective is particularly germane in understanding food consumption in tourism, for the phenomenon is closely linked to cultural values on one hand, and is regarded as a major conduit for experiencing the host culture on the other (Chang, et al., 2010; Kivela 
\& Crotts, 2006; Lee \& Crompton, 1992; Ondimu, 2002).

Under the tenets of world culture theory, an important consideration is the problem of 'globality' in terms of how to make living together in one global system meaningful or even possible (Lechner \& Boli, 2003). As Giddens (1996) states, globalisation is not just an 'out-there phenomenon' but an 'in here phenomenon' which affects the most intimate and personal aspects of our lives. Societies and individuals are increasingly aware of their 'global existence', and yet they are compelled to 'identify' themselves in new ways. Accordingly, globalisation can be viewed as a 'multidimensional' phenomenon, which comprises a complex mixture of homogeneity and heterogeneity (Robertson, 2001). Appadurai (1996) contends that whilst the globalisation force homogenises the world to some extent, the disjunctures in globalisation also produce heterogeneity. As such, the central feature of the 'global culture' is the politics of the mutual effort of sameness and difference to 'cannibalise' one another. He further points out that 'both sides of the coin of global cultural process today are products of the infinitely varied mutual contest of sameness and difference on a stage characterised by radical disjunctures between different sorts of global flows and the uncertain landscapes created in and through those disjunctures' (Appadurai, 1996, p. 43).

Adopting the concept of world culture theory that globalisation comprises a complex combination of homogeneity and heterogeneity, Robertson (1995) articulates the theory of 'glocalisation' to encapsulate the essence of this difference-within-sameness. Based on the postulate of the theory, globalisation is viewed as a dialectical process, one which is simultaneously 'the universalisation of the particular and the particularisation of the universal' (Robertson, 1995, p. 25). The theory recognises that globalisation features the critical reconstruction and reinvention of local cultures in relation to other cultural entities. When combined with the world culture theory, the theory of 'glocalisation' can be used to 'analyse the ways in which social actors construct meanings, identities and institutional forms within the sociological context of globalisation, conceived in multidimensional terms' (Giulianotti \& Robertson, 2006, p. 171). This concept is essential in understanding the tension between homogenisation and heterogenisation based on the concepts of 'global consciousness' and 'local consciousness'. When faced with increasingly homogeneous global products or ideas, people tend to interpret them in different ways and integrate them into their lives in diverse ways (Lechner \& Boli, 2003). Global products or ideas can be accepted, be adapted to suit the local needs by the 'glocalisation' process, or be rejected, thereby leading to the reconstruction and reinvention of local traditions or forms of particularity vis-à-vis other cultural entities 
(Robertson, 1995).

Hannerz (1992) argues that although many cultures are increasingly becoming subcultures within the 'global culture', these subcultures can still maintain a certain degree of differentiation, thereby implying a conceptual differentiation of 'global culture' and 'local culture'. He contends that the relationships between the 'core' and the 'periphery' involve diffusion as well as differentiation, and new culture can be generated at the periphery through the creative use of imported as well as local resources, a phenomenon which he refers to as the 'creolisation' of global culture. Analogous to creole languages formed by the unique combinations of languages, creole cultures come out of multidimensional cultural encounters. Hannerz (1992) further points out that the creolisation processes do not simply involve a constant pressure from the core towards the periphery, but involve a much more creative interplay. In fact, creolisation increasingly allows the periphery to 'respond', as it creates a greater affinity between the cultures of the core and the periphery. Kaplan and Lööw (2002) hold a similar view that whilst globalisation would have impacted our milieu, yet, oppositional subcultures would emerge to challenge the forces of globalisation in the dominant culture. Based on the preceding discussion, this paper adopts the world culture theory as the theoretical framework for understanding the influence of globalisation on food in tourism. In particular, three dichotomous dimensions are identified from the framework in examining the consequences of globalisation of culinary supply in destination: 'homogenisation' versus 'heterogenisation', 'global consciousness' versus 'local consciousness', and 'global culture' versus 'local culture'.

\section{Food Consumption in Tourism: Perspectives and Dimensions}

Food consumption in the general context, especially in the form of 'dining out', has been widely discussed in sociological literature (e.g., Finkelstein, 1998; Fischler, 1988; Warde \& Martens, 2000; Wood, 1995). Nonetheless, food consumption in tourism, a unique form of eating which occurs in a foreign and unfamiliar context, has been largely ignored in the discourse of tourism (Cohen \& Avieli, 2004). Food consumption in tourism and dining out are closely related, but not identical phenomena. A review of the tourism literature has revealed the idiosyncratic features of food consumption in tourism: it is largely essential (tourists need to eat when they travel away from home, unless they bring home food to the destination), it occurs in a foreign and unfamiliar contexts (in terms of food and foodways), it is of a 
temporal nature (tourists are usually in a sojourn instead of staying in the destination for a prolonged period of time), and it bears symbolic meaning and can be associated with travel motivation (Chang, et al., 2010; Cohen \& Avieli, 2004; Kivela \& Crotts, 2006; Richards, 2002).

The growing body of literature of food consumption in tourism can be distinguished into four broad perspectives: food as a tourist product/attraction, tourists' food consumption behaviour/pattern, tourists' dining experiences, and tourists' special interests in various food and beverages and related events/activities in destinations (e.g., food tourism, wine tourism, food events). The first perspective focuses on how food and gastronomic products can be utilised as a source of tourist product or attraction, usually by adopting a destination marketer's perspective (e.g., Hjalager \& Richards, 2002; Meler \& Cerovic, 2003). The second perspective is concerned with the type of cuisine/food tourists prefer and consume in destinations, the perceived functional and symbolic importance of the cuisine/food chosen, and the salient factors influencing tourists' consumption (e.g., Chang, et al., 2010; Kim, et al., 2009; Torres, 2002, 2003; Tse \& Crotts, 2005). The third perspective examines how tourists interpret the dining or meal experience (in some cases including service quality and restaurant attributes) in the overall tourist experience, and the factors affecting their evaluation and satisfaction (e.g., Chang, Kivela, \& Mak, 2011; Cohen \& Avieli, 2004; Kivela \& Crotts, 2006; Quan \& Wang, 2004). The fourth perspective focuses on tourists whose major motivation to visit a destination is for the food and beverages, or food-related events/activities in the destination locality, often referred to as gastronomy or culinary tourism (e.g., Galloway, et al., 2008; Long, 2004; Sparks, 2007).

From the tourist product/attraction perspective, there are generally two schools of thought regarding food in tourism - one sees food as a promising 'attraction' (Hjalager \& Richards, 2002), whereas the other views it as a potential 'impediment' to discourage tourists to visit a destination (Cohen \& Avieli, 2004). This schism is principally based on the different emphasis placed on the 'symbolic' importance as well as the 'obligatory' nature (Richards, 2002) of food consumption in tourism. Generally, food consumption in tourism is recognised as a 'symbolic' form of consumption. Certain 'cultural' theories pertaining to food consumption and dining out in the general context are adopted to explicate the 'symbolic' nature of food consumption in tourism, for example, the cultural capital theory. Cultural capital, as one of the four species of capital proposed by Bourdieu (1984), refers to a stock of knowledge and experience people acquire through the course of their lives that enables them to succeed more 
than someone with less cultural capital. Cultural capital enables individuals to interpret various cultural codes, and to impart their point of views regarding certain topics within the cultural group (Bourdieu, 1984; Bourdieu \& Wacquant, 1992). Cultural capital can be further distinguished into three states, namely, the embodied state (the knowledge and skills an individual possesses), the objectified state (expressed in a form of cultural goods), and the institutionalised state (represented by actual documents and other proof of cultural status). The embodied state is particularly relevant to food consumption in tourism, as empirical evidence suggests that many tourists consider partaking local food as a way to accrue knowledge on local food, as well as on local foodways and culture (Chang, et al., 2010; Kim, et al., 2009). This kind of cultural capital can be used immediately within the destination, be used on return to home, and even in future travel situations, which serves as an indication of the cultural sophistication of the tourist (e.g., be competent to appreciate and enjoy foreign food, and are sophisticated enough to be able to order it and eat it with proper manners) (Chang, et al., 2010; Cohen \& Avieli, 2004).

On the other hand, food consumption in tourism also possesses an 'obligatory' nature (Richards, 2002). As Quan and Wang (2004, p. 302) put it, 'a large portion of food consumption in tourism can be seen as the supporting experience for tourists to complete or realize their main purpose of travel'. Therefore, it would be too simplistic to focus only on the 'symbolic' side and ignore the 'obligatory' aspect of food consumption in tourism. Instead of pursuing the 'symbolic' facet of food, tourists may also be seeking 'ontological comfort of home' (Quan \& Wang, 2004, p. 301). As such, food-related personality traits, such as food neophobia (human's intrinsic fear of new food items) (Chang, et al., 2010; Chang, et al., 2011; Cohen \& Avieli, 2004; Kim, et al., 2009) can significantly affect food consumption in tourism. Fischler (1988, p. 278) aptly describes the tension between the neophobic and neophilic tendencies as the 'omnivore's paradox', one that constantly lives in 'the oscillation between the two poles of neophobia (prudence, fear of the unknown, resistance to change) and neophilia (the tendency to explore, the need for change, novelty, variety)'. To paraphrase Fischler, food consumption in tourism can be seen as the 'tourist's paradox', an oscillation between pursuing the 'symbolic' and fulfilling the 'obligatory' facets in the encounter of food in destinations.

'Novelty' and 'familiarity' are the two most general categories of interpretation of the world (Schuetz, 1971), and are particularly useful in understanding and interpreting tourist behaviour. According to Cohen (1972), tourists travel in quest of novelty; yet, most of them 
need an 'environmental bubble' (a certain degree of familiarity) of their home environment in order to fully enjoy the tourist experience. This is particularly so for food consumption in tourism, due to the neophobic tendency explained earlier. Hence, despite the fact that the desire to seek novel food and dining experiences can be one of the major motivations to visit a destination (Kivela \& Crotts, 2006), many tourists also need a certain degree of familiarity, especially in the case of Western tourists visiting destinations in developing countries (Cohen \& Avieli, 2004), where foods are typically unfamiliar and foodways alien. Interestingly, Chang et al (2010) also found that for tourists who are enthusiastic to sample local food, their 'core' food preference may still be dominant, reflecting again the 'tourist's paradox' between the desire to seek both novelty and familiarity.

From the tourist experience perspective, food consumption in tourism can be conceptually distinguished into 'supporting consumer experience' and 'peak touristic experience' (Quan \& Wang, 2004). This distinction is based on food consumption's relationship to tourists' daily routine, whether it is contrasting, intensifying, or extending the daily routine experience. In other words, this approach accentuates the concepts of 'contrast' and 'extension' in interpreting food consumption in tourism. Travel has long been associated with experiencing 'Otherness' (Otherness denotes the sense of the strange and unfamiliar created from specific subject positions, which provide clear boundaries that divide individuals, cultures and races), or in Urry's (2002) term to 'gaze' upon new sights and experiences that are 'out of the ordinary'. For many tourists, consuming local delicacies and participating in local foodways are essential parts of the tourist experience (Chang, et al., 2010). Conversely, some of the food experience can also be an 'extension' of the daily routine. As Giddens (1991) contends, daily routine provides a person with a source of comfort, relaxation, and ease, and thus, 'ontological security'. This sense of security can be extended to the context of food consumption in tourism, as Quan and Wang (2004, p. 301) put it 'ontological comfort of home' can help 'overcome anxieties and unfitness caused by unfamiliar environments on journey'.

Cohen and Avieli (2004) emphasise that due to the 'bodily involvement' of food, the risk posed by food consumption experiences is higher than other forms of tourist experience. For instance, viewing the cooking process of deep fried bugs by street vendors in Bangkok may elicit feelings of repulsion amongst certain tourists (Elsrud, 2001) even though the act of viewing involves much less risk than consuming the insects themselves. In this sense, the 'extension' dimension is indispensible for many tourists with regard to food consumption in a 
foreign context (Quan \& Wang, 2004). In summary, the preceding discussion identifies 'symbolic' versus 'obligatory', 'novelty' versus 'familiarity', and 'contrast' versus 'extension' as important dichotomous dimensions underlying food consumption in tourism. It is important to point out that, these classifications are conceptually differentiated in order to provide a theoretical framework for understanding the interplay between globalisation and food consumption in tourism. In reality, they are interchangeable and interdependent (Quan \& Wang, 2004).

\section{Globalisation and Culinary Supply in Destination}

World culture theory provides a macro framework in understanding the impact of globalisation on culinary supply in destination. Under this framework, globalisation can be viewed as a dialectical process between 'globalisation' and 'localisation', one that universalises the particular and particularises the universal (Robertson, 1995). The tension between globalisation and localisation is conceptually a dialectical and interdependent one. The tension is hypothesised to affect culinary supply in destination, as depicted in Figure 1. Whilst globalisation is contributing to a more homogenised culinary supply on one hand, the tension between globalisation and localisation is producing more diversity on the other (Hall, et al., 2008; Hall \& Sharples, 2008). In particular, the influence of globalisation and localisation can be conceptually distinguished into three dichotomous dimensions as previously identified: homogenisation versus heterogenisation, global consciousness versus local consciousness, and global culture versus local culture.

\section{* please insert Figure 1 about here}

Homogenisation versus Heterogenisation. One of the most contentious aspects of globalisation is its cultural implications, whether it leads to universal cultural uniformity, or leaves room for particularism and cultural diversity (Ram, 2004). Yet, the influence of globalisation on food supply and cuisine is not a new phenomenon. Hall and Mitchell (2002b) distinguish three major periods of rapid change to regional cuisine: the first wave was the period of European mercantilism from the late 1400s to the 1800s, the second wave was the influence of large-scale migrations from the seventeenth century to the twentieth century, and the third wave is the current period of globalisation of cuisine promoted by advances in communication and transport technology. Indeed, with the rapid technological advancement, contemporary globalisation has influenced food systems around the world in an 
unprecedented manner, bringing about changes and resulting in the greater availability and diversity of food (Kennedy, Nantel, \& Shetty, 2004).

The main drivers of the contemporary changes in food systems and food consumption patterns include urbanisation, increased income, market liberalisation, and foreign direct investment (Kennedy, et al., 2004). Amongst these drivers, market liberalisation and foreign direct investment are considered particularly crucial in contributing to the homogenising aspect of consumer food consumption. Whilst market liberalisation allows food to be sourced from all over the world, foreign direct investment such as investment by multinational food corporations has contributed to a more diverse food supply throughout the world, thereby accelerating the convergence of food consumption. For example, there are 31,967 McDonald's restaurants in more than 100 countries worldwide (McDonald's, 2011), and there are 4,588 Starbucks coffee international stores in 43 countries outside the United States (Starbucks, 2011). Likewise, Symons (1993, p. 11) states that 'food corporations are truly worldwide. We consume the same hamburgers, pizzas and cola drinks in what has become very much a world cuisine'.

The homogenising force of globalisation is often viewed as a threat to the authenticity of food (Leitch, 2009; Pilcher, 2006). Yet, it is important to point out that authenticity has long been regarded as a highly contentious issue in the tourism literature; the concept is especially debatable in the context of food consumption in tourism (Hall \& Mitchell, 2002b). It is generally agreed that food cultures do not remain static but are continually evolving and changing in response to different internal and external stimuli (Mennell, 1985; Molz, 2004). Hence, it is difficult if not impossible to define authenticity in food cultures. Wang (1999) differentiates various notions of authenticity into 'objective authenticity', 'constructive authenticity', and 'existential authenticity'. He (1999, p. 352) emphasises that 'authentic experiences in tourism and the authenticity of toured objects are constitutive of one another', thus, the authenticity of toured objects is in fact 'symbolic authenticity'. Cohen (2002) advocates that the emphasis should be shifted from academic debates about authenticity to how the concept is understood and interpreted by the tourists themselves. In a similar vein, Uriely (2005, p. 209) calls for 'a transformed focus from the toured objects to the tourist subjective negotiation of meanings'. The complex and multifaceted nature of the authenticity concept makes it a topic worthy of separate investigation in its own right.

Whilst one perspective views the homogenising force as a great threat to authenticity of 
food products that brings about cultural imperialism (Tomlinson, 1991) and McDonaldisation (Ritzer, 1995), world culture theory provides a contrasting 'two-way' perspective(Ram, 2004). This perspective emphasises that increased interactions between globalisation and localisation can result in heterogenisation (Appadurai, 1996). For example, in Ram's (2004) elaboration on how McDonaldisation has changed the culinary 'habitus' of Israel (habitus in Bourdieu's (1984) sense refers to the structure of disposition or propensities toward action which can be expressed inwardly or outwardly), it was found that McDonaldization did not bring about the demise of the local delicacy 'falafel', but instead contributed to the appearance of a new commodified version of it. Falafel is fried chickpea balls (or fava bean in Egypt) served in a 'pocket' of pita bread. Whilst the origins of the delicacy can be traced to the Christian Copts of Egypt, it has been assimilated and adopted in Israel as its 'national food'(Ram, 2004). The assimilation and transformation processes of falafel into an icon of Israeli culture can be regarded as part of the globalising process for they involved the Second and Third Aliyah (Jewish immigrants to Israel) (Raviv, 2003).

Concerns were raised when the first McDonald's opened in Israel in 1993, especially about its impact on the local food culture and eating 'habitus' (Bourdieu, 1984). Yet, the advent of McDonald's, or rather the general McDonaldisation of Israeli food habits, has led to the falafel's 'renaissance'. The revival of falafel is manifested in two distinct forms: 'gourmetised' and 'McDonalised'. The 'gourmetised' falafel has been transformed into clean and refined delicacy which comes in a variety of flavours, and is served in prestigious restaurants located in financial districts. The 'McDonaldised' version has been standardised and modified into clean, fresh and healthy fast-food, which is served indoors, at spruce, air-conditioned outlets. The standardised falafel is also branded and marketed globally through new international franchise chains such as the Maoz Vegetarian (Maoz, 2010). Accordingly, globalisation has not just contributed to the revival of the falafel, but also to the shift of the delicacy from parochialism to globalism (Ram, 2004). This exemplifies how globalisation produces homogenisation, and concomitantly provides impetus for transforming the nature and meaning of the local, which engenders heterogenisation (Appadurai, 1996).

Global Consciousness versus Local Consciousness. Hall and Mitchell (2000; 2002b) likewise emphasise that despite the rapid globalisation of the food market in many destinations, homogenisation of production or consumption is not a certainty. They argue that major local and regional eating patterns will remain, and in some circumstances, may even grow. This is manifested in the increasing awareness of cultural preferences and differences 
by many multinational food corporations. For instance, McDonald's has introduced 'localised' products such as 'McKroket' in the Netherlands, 'McKebab' in India, 'Teriyaki Burger' in Japan, and 'McRice Burger' in Hong Kong. In Israel, McDonald's has adjusted the preparation technique (by using a combined fire and charcoal) and the portion size (increased by 25 percent) of its hamburger in order to respond to the Israeli customers' preference for large portion of grilled meat (Ram, 2004). These examples suggest that the 'consciousness' of cultural differences between the global and local ('global consciousness' and 'local consciousness') displayed by multinational food corporations has resulted in an increased diversity of food products and have not suppressed local cultures.

Porter (1990, p. 19) emphasises that 'competitive advantage is created and sustained through a highly localised process', suggesting that differences in national economic structures, values, cultures, institutions and histories can contribute profoundly to competitive success. Porter's notion is particularly compatible with the theory of 'glocalisation' (Robertson, 1995), which suggests that globalisation of culture does not necessarily lead to the homogenisation of local cultures. On the contrary, the theory recognised that the critical reconstruction and reinvention of local cultures as one of the major consequences of globalisation. As such, the 'consciousness' of cultural differences between the global and local, and the subsequent 'glocalisation' process have become a competitive advantage in oligopolistic competitions amongst multinational food corporations. The 'consciousness' of local culinary traditions are equally important in the context of global tourism marketing. For example, the Hong Kong Tourism Board (Hong Kong Tourism Board, 2009a), with support from local restaurants, hotels, food experts, gourmets, and celebrity chefs, launched the 'Hong Kong Food and Wine Year' campaign in 2009 to actively promote local delicacies and international culinary offerings available in Hong Kong. As a former British colony, Hong Kong is a highly Westernised global city (Fung, 2008) juxtaposed with distinct local culture and traditions. Hence, in addition to featuring the 'global' culinary offerings, one of the key highlights of the campaign was the introduction of 'flavours of Hong Kong' and 'food stories' which offered a critical reconstruction and reinterpretation of the local culinary culture and traditions.

Global Culture versus Local Culture. World culture theory proposes an increased interaction between the global culture and local culture under the influence of globalisation. Vargas Llosa (2001) contends that globalisation will not eliminate local cultures, on the contrary, the increasingly interconnected and interdependent world will create incentives for 
new generations to learn and assimilate to other cultures. Hence, 'global culture' and 'local culture' can co-exist, whilst the global transformed the nature and meaning of the local, and the local in turn caused modification of the global (Ram, 2004). In some cases, the dialectical relationship between the 'global culture' and 'local culture' can lead to a 'creolisation' of food culture, manifested in a variety of 'fusion' or 'creolised' cuisines. For example, the 'New Asia-Singapore Cuisine' is a new cuisine developed and promoted by the Singapore Tourism Board. Singapore is a multiethnic state (comprises 77\% Chinese, 14\% Malays, and 8\% Indians) (Tan, et al., 2006), it is also one of the most Westernised and globalised countries in Asia (Lee, 2003). Consequently, there is a complex amalgam of Oriental versus Western, and 'global' versus 'local' cultures. The New Asia-Singapore Cuisine combines Oriental styles of ingredients, cooking process, and flavours with Western presentation techniques. It has been developed as a new breed of 'gastro-attractions' that have achieved great success in terms of public visibility and economic viability (Scarpato, 2002). Most significantly, the new cuisine is recognised as a new non-geographical and trans-ethnic 'creolised' cuisine created by the interplay between globalisation and localisation, representing an attitude that embraces modernity and respects local heritage. This exemplifies how 'global culture' can be blended with 'local culture' and happily co-exists to form a 'creolised' food culture.

\section{Globalisation and Food Consumption in Tourism}

Not only has globalisation significantly affected the culinary supply in destination, it has also been posited to exert considerable influence on food consumption in tourism. As the force of globalisation is recognised to produce homogenisation in consumer behaviour (Robertson, 2001), it can lead to a convergence in food consumption in tourism (Richards, 2002; Symons, 1993). On the other hand, the force of localisation is considered to bring about heterogenisation in consumer preferences (Appadurai, 1996); therefore, it may result in a divergence in consumption in tourism. Accordingly, food consumption in tourism is hypothesised to be affected by the dialectical force between convergence and divergence in food consumption (see Figure 2). The dialectical force between convergence and divergence in food consumption can be conceptually understood under three dichotomous dimensions: obligatory versus symbolic, familiarity versus novelty, and extension versus contrast.

\section{* please insert Figure 2 about here}

Symbolic versus Obligatory. The 'symbolic' aspects of food consumption in tourism can be significantly influenced by the convergence and divergence in food consumption. Food in 
tourism is widely recognised as an essential cultural element a destination has to offer (Scarpato, 2002). Molz's (2007) 'cosmopolitan mobilities' concept suggests that consuming the differences amongst various 'Others' is also performing a sense of adventure, adaptability, and openness to any other culture, thus implying a greater symbolic value in food experiences amongst post-modern tourists. One significant 'symbolic' aspect of food consumption in tourism is 'education'. The consumption of local food/beverages and participation in the local foodways is viewed as an important channel to acquire knowledge on local food and culture (Chang, et al., 2010; Kim, et al., 2009). Nonetheless, what kind of knowledge is regarded as important 'embodied cultural capital' in a 'field' (a 'field' in Bourdieu's (1984) terms refers to a configuration of position comprising agents struggling to maximise their position) is not static, and can be influenced by different degrees of convergence and divergence of food consumption. For instance, knowledge about wine (particularly red and white wine) has long been regarded as a form of cultural capital in Western societies; yet, due to the increasing convergence of wine consumption, there is a rising interest in Asian societies to acquire knowledge about wine appreciation and investment (Getz, et al., 1993). In a similar vein, knowledge about Western cuisines, such as iconic dishes, preparation methods, serving and table manners, is also increasingly regarded as important cultural capital for status and social distinction by Chinese tourists (Chang, et al., 2010).

Alternatively, the symbolic aspect of food consumption in tourism is juxtaposed with the obligatory facet, which is also subjected to the influence of convergence and divergence of food consumption. Molz (2007) points out that the openness to other cultures in terms of food consumption involves a certain amount of 'risk'. Cohen and Avieli (2004) contrast the conventional 'tourist gaze' (Urry, 2002) with 'gazing with the tongue' (Molz, 2007), emphasising that eating involves the body directly with the environment, and thus, has a higher potential risk. Nevertheless, increased exposure to and familiarity with other ethnic cuisines, as a result of globalisation and convergence of food consumption, may decrease the perceived risk. Contemporary globalisation has brought about an increased availability of ethnic restaurants in tourists' home settings as well as information sources about cuisines of the 'Others' (Cohen \& Avieli, 2004). Tourists generally have a wider exposure to foreign and unfamiliar food and cuisines based on increased travel opportunities, diversity of food supply, number of ethnic restaurants in their home settings, and availability of information sources from various forms of media, including the Internet. The increased exposure may allow tourists to acquaint themselves with a variety of foreign cuisines even though they have not 
yet visited the places wherein these cuisines originated. Although one might argue that foreign cuisines in tourists' home settings can be very different from those in the originating countries, they would at least allow tourists to gain a 'superficial' knowledge and exposure to the cuisines of the 'Other'.

Food choice research found that exposure to certain foods tends to increase preference for those foods, as familiarity increases with repeated exposure (Birch, et al., 1987; Pliner, 1982). In a similar vein, tourists' exposure to the local cuisine of a different culture, either acquired through previous visits or in their home settings, can increase the familiarity of that cuisine and thus potentially reduce the perceived risk associated with it. For instance, a British tourist who is used to frequenting YO! Sushi, a British restaurant chain that uses the Japanese style conveyor belt method of delivering sushi to its customers (YO!Sushi, 2009), will have an increased exposure and familiarity to the wide array of 'sashimi' (slices of raw fish) dishes available in the restaurant, and may be more willing to consume sashimi when he/she travels to Japan. This corroborates the notion that globalisation may lead to an increased interest in consuming local or ethnic food as many people around the world now have an increased exposure to a wider variety of ethnic dishes and products (Torres, 2002). The study conducted by Tse and Crotts (2005) supports this, indicating that repeat visitation was positively correlated with both the number and range of tourists' culinary explorations, whereas first-time visitation was negatively correlated. Likewise, Ryu and Jang (2006) found that past experience is one of the significant predictors of tourists' intention to consume local cuisine in destinations.

Novelty versus Familiarity. Globalisation is recognised to bring about an increased diversity and a greater availability of food and culinary supply (Kennedy, et al., 2004). Accordingly, not only have tourists become more mobile, so has the food they eat (Richards, 2002). As Calhoun (2002, p. 889) puts it, 'samosas are now English food just as pizza is American and Indonesian curry is Dutch. Even where the hint of the exotic (and the uniformity of the local) is stronger, one can eat internationally-Mexican food in Norway, Ethiopian in Italy'. Hence, contemporary globalisation has brought about a greater variety of culinary offerings for tourists, satisfying their desire to seek 'novelty' in the culinary sphere.

As previously stated, 'risk' is an inherent part of food consumption in tourism in terms of exposure to unfamiliar ingredients, hygiene, health risks, culinary settings and different flavours (Cohen \& Avieli, 2004). In addition, Fischler's (1988, p. 278) 'omnivore's paradox' 
suggests that a neophobic tendency can be a significant food-related personality trait that contextualises food consumption in tourism. Nonetheless, globalisation and convergence in food consumption may offer opportunities to alleviate these constraints by presenting tourists with certain degree of 'familiarity'. Whilst some tourists, particularly those travelling to developing countries, may avoid consumption of certain local foods due to unfamiliar ingredients (Cohen \& Avieli, 2004) and perceived hygiene and health risks such as traveller's diarrhoea (Torres \& Skillicorn, 2004), interestingly, many tourists are also reluctant to choose unfamiliar local food due to concerns about the 'risk of being unaccustomed' to its taste or flavour. For instance, Chang et al. (2010) found that many Chinese tourists travelling to Australia tend to avoid the risk of being unaccustomed to the taste of the local indigenous food and are inclined to seek a 'familiar flavour' from food that can offer them a sense of 'appetizing assurance'.

Yet, Australia is recognised as a modernised and globalised country with a wide plethora of gastronomic offerings. Its cuisine represents a creative merging of international styles which is largely influenced by migration from Europe and more recently from Asia (Hall \& Mitchell, 2002a). Ang (2000) points to the fact that Australian cuisine is commonly evoked in terms of its 'fusion' with Asian ingredients and tastes. In this sense, the 'creolised' Australian cuisine provides Chinese tourists a relatively higher level of 'familiarity' in terms of taste. As a result, globalisation and convergence in food consumption can increase tourists' exposure to and familiarity with foreign cuisines on one hand, they also contribute to a more diversified and 'glocalised' culinary supply in destinations on the other. Whilst there is increased diversity and 'novelty', there is also an increased 'familiarity' a destination has to offer. This would provide tourists with the 'ontological comfort of home' (Quan \& Wang, 2004), providing a solution to the 'tourist's paradox'.

Contrast versus Extension. Convergence and divergence in food consumption may affect how tourists perceive food consumption as an 'experience'. As previously discussed, food consumption in tourism can be conceptually distinguished into 'peak touristic experience' and 'supporting consumer experience' based on its relationship with tourist's daily experiences (Quan \& Wang, 2004). Generally, the peak touristic experience is in sharp 'contrast' with daily experiences, whereas supporting consumer experiences are mainly characterised by 'extension' and 'intensification' of daily experiences. The dialectical relationship between 
convergence and divergence in consumption can significantly influence tourists' pursuit of extension/intensification or contrast in their food consumption experience in a destination.

Theoretically, if there is an increasing level of convergence in consumption between a particular tourist market segment and the host destination, tourists may share a more homogenous consumption pattern with the host destination. The tourism dining experience would then become largely an extension or intensification of a tourist's daily routine due to a lower level of 'contrast' and 'novelty' element in the dining experience. Alternatively, if there is a high level of divergence in consumption between the tourist market segment and the host destination, tourists may exhibit a more heterogeneous consumption pattern in contrast with the host destination, and food consumption in tourism will be a 'contrast' to tourists' daily routine, thereby serving as one of the major conduits to experience the 'Otherness' of the destination.

It is important to point out that the effect of convergence and divergence on food consumption in tourism is still relatively unknown, as it has received little research attention. Although many are concerned that globalisation will result in a converging 'global palate' (Richards, 2002; Symons, 1993), evidence from consumer behaviour studies suggests that consumption behaviours are not converging across countries; instead, they are actually diverging. For example, Herrmann and Röder (1995) find that differences in preferences are more important determinants of food consumption levels than differences in income and the availability of food. Likewise, de Mooij and Hofstede (2002) contend that as consumer incomes converge across countries, cultural values will become prominent in explaining more differences in country-level consumption behaviour. In other words, the wealthier the countries become, the more they manifest the influence of culture on consumption. This implies that consumer behaviour may remain heterogeneous because of cultural differences. Furthermore, the experiential aspects of food consumption in tourism can further incite a sense of 'contrast'. For instance, consuming a food in a place where it has originated from or consuming a food in a memorable setting in a destination often provide a 'contrast' to daily routine experiences (even when tourists have tried the food in ethnic restaurants in their home countries). Chang et al.'s (2011) study identifies the experiential factor as an important attribute for evaluating travel dining experience. In some cases, the intangible experiential aspects may even outweigh tangible food quality in satisfying tourists' experiential needs. 
Based on the preceding discussion, an integrated conceptual model is developed to explain the overall influence of globalisation on local culinary supply and tourist food consumption (see Figure 3). First, following the tenets of world culture theory, globalisation is hypothesised to bring about convergence in food consumption. The convergence in turn will reinforce globalisation, and so the relationship can be viewed as being reciprocal (as indicated by the double arrow). Similarly, localisation is expected to result in the reinvention and the reconstruction of local cultures and identities, thereby contributing to divergence in food consumption. The divergence is expected to further stimulate localisation.

\section{* please insert Figure 3 about here}

Second, as elaborated earlier, it is suggested that the tension between globalisation and localisation may affect the culinary supply in destinations, manifested in three dichotomous dimensions (i.e., 'homogenisation' versus 'heterogenisation', 'global consciousness' versus 'local consciousness', and 'global culture' versus 'local culture'). Third, the extent of 'glocalisation' in culinary supply is expected to exert indirect influence on the globalisation and localisation in the destination, respectively (indicated by the dotted arrows). For example, in Hong Kong, English-style tea has evolved into a new local style of drink, with Hong Kong-style 'milk tea' using evaporated milk instead of fresh milk. Another common beverage featured in local cafés is 'yuan-yang', which is brewed from a mixture of tea and coffee (Hong Kong Tourism Board, 2009b). Both beverages have become celebrated 'glocalised' food products to tourists and local residents. These kinds of 'glocalised' culinary products not only affect the culinary supply in tourism but also indirectly influence the 'localisation' of the local food culture and identities.

Fourth, as previously discussed, the dialectal relationship between convergence and divergence in food consumption is proposed to result in a diversification in food consumption in tourism, which can be understood from three dichotomous dimensions (i.e., 'symbolic' versus 'obligatory', 'novelty' versus 'familiarity', and 'contrast' versus 'extension'). Fifth, the diversification in food consumption in tourism is expected to affect the convergence or divergence in food consumption indirectly (as indicated by the dotted arrows). Tourism can have a considerable impact on food production and consumption in a destination (Hall \& Mitchell, 2002b). For example, some culinary establishments may change or modify their menus and certain dishes to meet perceived tourist demands (Reynolds, 1993; Telfer \& Wall, 1996). As culinary establishments are rarely exclusive for tourists, this may also influence the 
taste and consumption of the local community. For example, it has been reported that a McDonald's outlet will soon be opened in the underground shopping-mall next to the Louvre Museum in Paris (Schofield, 2009). Apparently, the outlet aims to cater for tourists' diversified dining demand, providing an alternative to traditional French cuisine. Although the French generally regard McDonald's as part of an American cultural invasion (Willging, 2008), news of the opening of the McDonald's outlet next to the Louvre has not had as much impact on French people compared with the way they would have responded a decade ago (Schofield, 2009). Hence, the diversification in tourism dining demand may indirectly influence the taste and consumption patterns of the local residents. There are now more than 1,130 McDonald's restaurants and 90 McCafés in France. France is reported to be McDonald's second-most profitable market after the United States and is also the country where customers spend most money per visit (Schofield, 2009). Finally, 'glocalisation' of local culinary supply is hypothesised to exert a mutual influence on food consumption in tourism. For instance, a highly 'glocalised' culinary supply may lead to an increased interest in seeking 'contrast' and 'novelty' amongst tourists. On the other hand, tourists' desire to seek 'symbolic' meanings of food may provide further impetus for destination marketers and culinary suppliers to reinvent or reconstruct the local food culture and identities.

\section{CONCLUSION}

This paper has aimed to understand the interplay between globalisation and food consumption in the context of tourism. It has done so by examining the relevant sociological perspectives and theories of globalisation. Three dichotomous dimensions relevant to local culinary supply are proposed: 'homogenisation' versus 'heterogenisation', 'global consciousness' versus 'local consciousness', and 'global culture' versus 'local culture'. Second, by reviewing relevant tourism literature, three key dichotomous dimensions underlying food consumption in tourism have also been suggested: 'symbolic' versus 'obligatory', 'novelty' versus 'familiarity', and 'contrast' versus 'extension'. Based on the dimensions identified, a conceptual model has been developed in an attempt to illustrate the influence of globalisation on both the local culinary supply and food consumption in destinations. Considering the idiosyncratic nature of food consumption in tourism, it is essential to transcend the sociological approach and adopt a tourism-specific framework in understanding food consumption in tourism. The proposed model in this paper provides such a transcendent approach. Based on the review and the proposed conceptual model, future 
research and recommendations for destination markers and culinary suppliers are suggested.

\section{Limitations and Future Research Directions}

Given the scarcity of studies, both in applying globalisation theories in the tourism context in general, and in examining food consumption in tourism in particular, there are significant gaps in the existing literature with respect to this field of study. This paper is the first attempt to integrate the sociological and tourism perspectives to generate a better understanding of the impact of globalisation on local culinary supply and food consumption in tourism. The proposed model draws out the connections between globalisation and localisation, convergence and divergence in food consumption, and in particular, how they would affect the local culinary supply and tourist food consumption in destinations. However, it should be noted that the proposed model is only conceptual in nature and further empirical analysis would be necessary to confirm its utility. For example, from the perspective of the local culinary supply, future research could explore the forces of homogenisation and heterogenisation such as market liberalisation and foreign direct investment and their influences on local culinary 'habitus'. The degree of global or local consciousness (e.g., the level of local consciousness of multinational food corporations) provides a useful framework for studying the 'localising' process and diversity of food products in destinations. The relative impact of global and local culture on the 'creolisation' of the local culinary culture requires more investigation.

The symbolic and obligatory aspects of food consumption provide an innovative approach to examining tourist motivation and perception with regard to food choice and preference in destinations. In particular, the development of cultural capital through food and wine consumption in tourism, and how is such development affected by the force of convergence in food consumption are worthy areas for further exploration. The perception of familiarity, novelty, risk, and the level of extension and contrast tourists seek under the influence of globalisation represent new research directions. The interrelationship between local culinary supply and tourist food consumption, and how tourism influences food consumption (both in terms of tourism dining and consumption in tourists' home settings) (Astier-Dumas \& Mosse, 1985) offers important research opportunities. 
Although globalisation is expected to bring about increased homogenisation, this paper suggests that tourism dining demand will maintain a certain degree of heterogeneity (Hall \& Mitchell, 2002b; Ram, 2004). Hence, it is important for destination marketers and culinary suppliers to understand tourists' cultural values and preferences to develop and provide appropriate 'glocalised' or 'localised' gastronomic products (Chang, et al., 2010; Cohen \& Avieli, 2004; Quan \& Wang, 2004). For example, a group of Canadian federal and provincial tourism organisations carried out a survey of Travel Activities and Motivations to determine tourists' travel behaviours (Ignatov \& Smith, 2006). Although the survey mostly covered travel experiences and activities, one important area included related to food and wine activities (Stewart, Bramble, \& Ziraldo, 2008). This type of research would be useful to inform the development of effective strategies in the promotion and development of gastronomic products as well as serving as a basis for segmentation of the tourist market.

The reconstruction or reinvention of food culture and identities is essential in developing gastronomic products; it can also achieve competitive advantage (Porter, 1990). Hall and Mitchell $(2000 ; 2002 b)$ emphasise that globalisation is impossible without localisation, and that one of the great paradoxes of contemporary globalisation is the extent to which localisation has become significant (Hall, et al., 2008; Hall \& Sharples, 2008). Accordingly, some components of 'localism' are always involved in food consumption in the context of tourism. In this sense, local food identities do not necessarily suffer and may even benefit from globalisation (Ram, 2004). With tourism playing an important role, local food identities have the potential to grow under globalisation (Hall \& Mitchell, 2002b). Consequently, destination marketers and culinary suppliers should capitalise on this effect by emphasising the uniqueness of the local food culture and identities (Fox, 2007; Harrington, 2005). As stated earlier, Hong Kong has been actively promoting its unique local delicacies by featuring 'flavours of Hong Kong' and 'food stories' to reinforce its local food culture and traditions (Hong Kong Tourism Board, 2009a). Similarly, creolisation of food culture and fusion cuisines or dishes can be creative strategies for enriching the repertoire of gastronomic products in the destination. For instance, the 'New Asia-Singapore Cuisine', the 'Hong Kong-style milk tea' and 'yuan-yang' are some successful examples of a new breed of 'gastro-attractions', which provide tourists with distinctive, diversified, and novel culinary options.

Given the importance of the 'symbolic' aspects of food consumption in tourism, destination marketers and culinary suppliers may jointly promote the traditions and customs 
of the local food to enhance interest. In addition, gastronomic products can be linked with special activities and experiences available in the destination to augment the experiential aspects of the consumption experience. For example, the Museum of Tea Ware in Hong Kong is a museum dedicated to the appreciation and study of tea ware. It holds regular demonstrations, tea gatherings, and lecture programmes to promote ceramic art and the Chinese tea drinking culture (Luckow, 2009). As tea is an essential part of the Hong Kong food culture, the tea appreciation class offered by the museum can satisfy tourists' desire for acquiring cultural capital. Furthermore, various eating etiquettes, unique cooking methods, and 'grammar of food' (in Barthes' (1975) terms, food can be interpreted as signs in a system of communication) can be used to enrich the 'symbolic' side of gastronomic products.

Finally, destination marketers and culinary supplies can jointly investigate the possibility of introducing more local food and produce in culinary offerings. Local produce or local indigenous ingredients available under different geographical-climatic conditions and seasonality can stimulate tourists' quest for the geographical or historical 'sense of place' (Scarpato, 2002). Furthermore, as pointed out by Trubek (2008, p. 250), 'the taste of place' or 'terroir' can inspire and inform both culinary practices and values. Most importantly, the use of local food can reduce leakage and enhance sustainable development in the destination. This echoes Telfer and Wall's (2000) suggestion that if destinations are to maximise benefits from tourism development, they must strategically increase backward economic linkages, including utilising local food produce in the tourism industry. To conclude, globalisation can be seen as a threat but also an impetus that opens up new opportunities for reinvention of local gastronomic products and identities. From the world culture perspective, food identities and cultures do not necessarily suffer but instead benefit from the dialectical relationship between globalisation and localisation. Destination marketers and culinary suppliers should harness the

positive effects of globalisation by reviving and reconstructing local traditions and particularities for the tourism market.

\section{REFERENCES}

Ang, I. (2000). Introduction: Alter/Asian Cultural Interventions for 21st Century Australia. In I. Ang, S. Chalmers, L. Law \& M. Thomas (Eds.), Alter/Asians: Asian-Australian identities in art, media, and popular culture (pp. xiii-xxx). Sydney: Pluto Press.

Appadurai, A. (1996). Modernity at large: cultural dimensions of globalization. Minneapolis, MI: 
University of Minnesota Press.

Astier-Dumas, M., \& Mosse, A. (1985). Does Tourism Influence Food Choice. Biblthca Nutr. Dieta, $36,26-28$.

Barthes, R. (1975). Towards a psychology of contemporary food consumption. In E. Forster \& R. Forster (Eds.), European Diet form Pre-industrial to Modern Times. New York: Harper \& Row.

Bessiere, J. (1998). Local Development and Heritage: Traditional Food and Cuisine as Tourist Attractions in Rural Areas. Sociologia Ruralis, 38(1), 21-34.

Birch, L. L., McPhee, L., Shoba, B. C., Pirok, E., \& Steinberg, L. (1987). What Kind of Exposure Reduces Children's Food Neophobia. Appetite, 9, 171-178.

Bourdieu, P. (1984). Distinction: A Social Critique of the Judgement of Taste. Cambridge, MA: Harvard University Press.

Bourdieu, P., \& Wacquant, L. (1992). An invitation to reflexive sociology. Chicago: University of Chicago Press.

Calhoun, C. (2002). The Class Consciousness of Frequent Travelers: Toward a Critique of Actually Existing Cosmopolitanism The South Atlantic Quarterly, 101(4), 869-897.

Chang, R. C. Y., Kivela, J., \& Mak, A. H. N. (2010). Food preferences of Chinese tourists. Annals of Tourism Research, 37(4), 989-1011.

Chang, R. C. Y., Kivela, J., \& Mak, A. H. N. (2011). Attributes that Influence the Evaluation of Travel Dining Experience: When East meets West. Tourism Management, 32(2), 307-316.

Cohen, E. (1972). Toward a Sociology of International Tourism. Social Research, 39, 174-182.

Cohen, E. (2002). Authenticity, equity and sustainability in tourism. Journal of Sustainable Tourism, 10(4), 267-276.

Cohen, E., \& Avieli, N. (2004). Food in Tourism: Attraction and Impediment. Annals of Tourism Research, 31(4), 755-778.

de Mooij, M., \& Hofstede, G. (2002). Convergence and divergence in consumer behavior: implications for international retailing. Journal of Retailing, 78(1), 61-69.

Elsrud, T. (2001). Risk Creation in Travelling: Backpacker Adventure Narration. Annals of Tourism Research, 28(3), 597-617.

Finkelstein, J. (1998). Dining Out: The Hyperreality of Appetite. In R. Scapp \& B. Seitz (Eds.), Eating Culture (pp. 201-215). Albany: State University of New York Press.

Fischler, C. (1988). Food, Self and Identity. Social Science Information, 27, 275-292.

Fox, R. (2007). Reinventing the gastronomic identity of Croatian tourist destinations. International Journal of Hospitality Management, 26, 546-559.

Fung, A. (2008). Discourse and Cultural Identity: Towards a Global Identity for Hong Kong. In D. D. Wu (Ed.), Discourses of Cultural China in the Globalizing Age (pp. 189-202). Hong Kong: Hong Kong University Press.

Galloway, G., Mitchell, R., Getz, D., Crouch, G., \& Ong, B. (2008). Sensation seeking and the 
prediction of attitudes and behaviours of wine tourists. Tourism Management, 29(5), 950-966.

Getz, D., Dowling, R., Carlsen, J., \& Anderson, D. (1993). Critical Success Factors for Wine Tourism. International Journal of Wine Marketing, 11(3), 20-43.

Giddens, A. (1990). The Consequences of Modernity. Cambridge: Polity Press.

Giddens, A. (1991). Modernity and self-identity: self and society in the late modern age. California: Stanford University Press.

Giddens, A. (1996). Affluence, poverty and the idea of a post-scarcity society. Development and Change, 27, 365-377.

Giulianotti, R., \& Robertson, R. (2006). Glocalization, Globalization and Migration: The Case of Scottish Football Supporters in North America. International Sociology, 21(2), 171-198.

Hall, C. M., \& Mitchell, R. (2001). Wine and Food Tourism. In N. Douglas \& R. Derrett (Eds.), Special Interest Tourism: context and cases (pp. 307-329). Brisbane: John Wiley.

Hall, C. M., Mitchell, R., Scott, D., \& Sharples, L. (2008). The authentic market experience of farmers' markets. In C. M. Hall \& L. Sharples (Eds.), Food and Wine Festivals and Events Around the World: Development, Management and Markets (pp. 197-231). Oxford: Butterworth Heinemann.

Hall, C. M., \& Mitchell, R. D. (2000). We are what we eat: tourism, culture and the globalisation and localisation of cuisine. Tourism Culture and Communication, 2(1), 29-37.

Hall, C. M., \& Sharples, L. (2003). The consumption of experiences or the experiences of consumption? An introduction to the tourism of taste. In C. M. Hall, E. Sharples, R. Mitchell, N. Macionis \& B. Cambourne (Eds.), Food Tourism Around the World: development, management and markets (pp. 1-24). Oxford: Butterworth-Heinemann,.

Hall, C. M., \& Sharples, L. (2008). Food events, festivals and farmers' markets: An introduction. In C. M. Hall \& L. Sharples (Eds.), Food and Wine Festivals and Events Around the World: Development, Management and Markets (pp. 3-22). Oxford: Butterworth Heinemann.

Hall, M., \& Mitchell, R. (2002a). The Changing Nature of the Relationship Between Cuisine and Tourism in Australia and New Zealand: from Fusion Cuisine to Food Networks. In A. M. Hjalager \& G. Richards (Eds.), Tourism and Gastronomy (pp. 187-206). London: Routledge.

Hall, M., \& Mitchell, R. (2002b). Tourism as a force for gastronomic globalization and localization. In A. M. Hjalager \& G. Richards (Eds.), Tourism and Gastronomy (pp. 71-90). London: Routledge.

Hannerz, U. (1992). Cultural Complexity: Studies in the social organization of meaning. New York: Columbia University Press.

Harrington, R. J. (2005). Defining gastronomic identity: The impact of environment and culture on prevailing components, texture and flavors in wine and food. Journal of Culinary Science and Technology, 4(2-3), 129-152.

Herrmann, R., \& Röder, C. (1995). Does food consumption converge internationally? Measurement, empirical tests and determinants. European Review of Agricultural Economics, 22, 400-414. 
Hjalager, A. M., \& Richards, G. (Eds.). (2002). Tourism and Gastronomy. London: Routledge. Hong Kong Tourism Board. (2009a). Hong Kong Food and Wine Year - HK Must Taste! Retrieved 23 October, 2009, from http://www.discoverhongkong.com/hkfoodandwineyear/eng/must taste/intro.jsp

Hong Kong Tourism Board. (2009b). Hong Kong Tea Culture. Retrieved Nov, 16, 2009, from http://www.discoverhongkong.com/eng/dining/tea-hongkong.html

Ignatov, E., \& Smith, S. (2006). Segmenting Canadian Culinary Tourists. Current Issues in Tourism, 9(3), 235-255.

Inglis, D., \& Gimlin, D. (Eds.). (2009). The Globalization of Food. Oxford: Berg Publishers.

Jenkins, R. (2004). Globalization, production, employment and poverty: debates and evidence. Journal of International Development, 16(1), 1-12.

Kaplan, J., \& Lööw, H. (2002). The Cultic Milieu: Oppositional Subcultures in an Age of Globalization. Walnut Creek, CA: AltaMira Press.

Kennedy, G., Nantel, G., \& Shetty, P. (2004). Globalization of food systems in developing countries: a synthesis of country case studies Globalization of food systems in developing countries: impact on food security and nutrition (FAO Food and Nutrition Paper No. 83) (pp. 1-26). Rome: Food and Agriculture Organization of the United Nations.

Kim, Y. G., Eves, A., \& Scarles, C. (2009). Building a Model of Local Food Consumption on Trips and Holidays: A Grounded Theory Approach. International Journal of Hospitality Management, 28, 423-431.

Kivela, J., \& Crotts, J. C. (2006). Tourism and Gastronomy: Gastronomy's Influence on How Tourists Experience a Destination. Journal of Hospitality and Tourism Research, 30(3), 354-377.

Lang, T. (1999). The complexities of globalization: The UK as a case study of tensions within the food system and the challenge to food policy. Agriculture and Human Values, 16, 169-185.

Lechner, F. J., \& Boli, J. (2003). Part II Explaining Globalization - Introduction. In F. J. Lechner \& J. Boli (Eds.), The Globalization Reader (2nd ed., pp. 55-57). Malden: Blackwell Publishers.

Lee, C. Y. (2003). Do traditional values still exist in modern Chinese societies? The case of Singapore and China. Asia Europe Journal, 1, 43-59.

Lee, T., \& Crompton, J. (1992). Measuring Novelty Seeking in Tourism. Annals of Tourism Research, 19, 732-737.

Leitch, A. (2009). Slow Food and the Politics of 'Virtuous Globalization'. In D. Inglis \& D. Gimlin (Eds.), The Globalization of Food (pp. 45-64). Oxford: Berg Publishers.

Long, L. M. (2004). Culinary Tourism. Kentucky: The University Press of Kentucky.

Luckow, T. (2009). Museum of Tea Ware. Retrieved Nov, 18, 2009, from http://www.lcsd.gov.hk/CE/Museum/Arts/english/tea/tea.html

Maoz. (2010). History. Retrieved June, 28, 2010, from http://www.maozusa.com/

McDonald's. (2011). McDonald's Corporation Annual Report 2010. Chicago: McDonald's Corporation. 
Meler, M., \& Cerovic, Z. (2003). Food marketing in the function of tourist product development. British Food Journal, 105(3), 175-192.

Mennell, S. (1985). All Manners of Food: Eating and Taste in England and France from the Middle Ages. Oxford: Blackwell.

Molz, J. G. (2004). Tasting an Imagined Thailand: Authenticity and Culinary Tourism in Thai Restaurants. In L. M. Long (Ed.), Culinary Tourism (pp. 53-75). Lexington: The University Press of Kentucky.

Molz, J. G. (2007). Eating Difference: The Cosmopolitan Mobilities of Culinary Tourism. Space and Culture, 10(1), 77-93.

Morgan, K., Marsden, T., \& Murdoch, J. (2006). Worlds of food: place, power, and provenance in the food chain. Oxford: Oxford University Press.

Ondimu, K. J. (2002). Cultural Tourism in Kenya. Annals of Tourism Research, 29(4), 1036-1047.

Oosterveer, P. (2006). Globalization and sustainable consumption of shrimp: consumers and governance in the global space of flows. International Journal of Consumer Studies, 30(5), 465-476.

Pilcher, J. M. (2006). Taco Bell, Maseca, and Slow Food: A Postmodern Apocalypse for Mexico's Peasant Cuisine? In R. Wilk (Ed.), Fast food/slow food: the cultural economy of the global food system (pp. 69-82). Plymouth: AltaMira Press.

Pliner, P. (1982). The Effects of Mere Exposure on Liking for Edible Substances. Appetite, 2, 283-290.

Porter, M. E. (1990). Competitive Advantage of Nations. New York: Free Press.

Quan, S., \& Wang, N. (2004). Towards a Structural Model of the Tourist Experience: An Illustration from Food Experience in Tourism. Tourism Management, 25(3), 297-305.

Ram, U. (2004). Glocommodification: How the Global Consumes the Local - McDonald's in Israel. Current Sociology, 52(1), 11-31.

Raviv, Y. (2003). Falafel: A National Icon. Gastronomica, 3(3), 20-25.

Reiser, D. (2003). Globalisation: An old phenomenon that needs to be rediscovered for tourism? Tourism and Hospitality Research, 4(4), 306-320.

Reynolds, P. C. (1993). Food and tourism: towards an understanding of sustainable culture. Journal of Sustainable Tourism, 1(1), 48-54.

Richards, G. (2002). Gastronomy: An Essential Ingredient in Tourism Production and Consumption? In A. M. Hjalager \& G. Richards (Eds.), Tourism and Gastronomy (pp. 3-20). London: Routledge.

Ritzer, G. (1995). The McDonaldization of Society. London: Sage.

Robertson, R. (1992). Globalization: Social Theory and Global Culture. London: Sage.

Robertson, R. (1995). Glocalization: Time-Space and Homogeneity-Heterogeneity. In $M$. Featherstone, S. Lash \& R. Robertson (Eds.), Global Modernities (pp. 25-44). London: Sage.

Robertson, R. (2001). Globalization Theory 2000+: Major Problematics. In G. Ritzer \& B. Smart (Eds.), Handbook of Social Theory (Vol. 458-471). London: Sage. 
Ryu, K., \& Jang, S. (2006). Intention to experience local cuisine in a travel destination: the modified theory of reasoned action. Journal of Hospitality and Tourism Research, 30(4), 507-516.

Scarpato, R. (2002). Gastronomy as a Tourist Product: The Perspective of Gastronomy Studies. In A. M. Hjalager \& G. Richards (Eds.), Tourism and Gastronomy (pp. 51-70). London: Routledge.

Schmelzkopf, K. (2002). Interdisciplinarity, Participatory Learning and the Geography of Tourism. Journal of Geography in Higher Education, 26(2), 181-195.

Schofield, H. (2009, 10 October 2009). McDo: A love-'ate relationship? BBC News, Paris Retrieved from http://news.bbc.co.uk/1/hi/world/europe/8297365.stm

Schuetz, A. (1971). Collected Papers. Vol. 1, The Problem of Social Reality. The Hague: Martinus Nijhoff.

Smith, S. L. J., \& Xiao, H. (2008). Culinary tourism supply chains: a preliminary examination. Journal of Travel Research 46(3), 289-299.

Sparks, B. (2007). Planning a wine tourism vacation? Factors that help to predict tourist behavioural intentions. Tourism Management, 28(5), 1180-1192.

Starbucks. (2011). Starbucks Company Profile. Retrieved September 3, 2011, from http://news.starbucks.com/images/10041/AboutUs-CompanyProfile-Q3-2011-7_28 11-FINA $\underline{\text { L.pdf }}$

Stewart, J. W., Bramble, L., \& Ziraldo, D. (2008). Key challenges in wine and culinary tourism with practical recommendations. International Journal of Contemporary Hospitality Management, 20(3), 302-312.

Symons, M. (1993). The Shared Table: Ideas for Australian Cuisine. Canberra: AGPS.

Tan, L. C. S., Lau, P.-N., Jamora, R. D. G., \& Chan, E. S. Y. (2006). Use of complementary therapies in patients with Parkinson's disease in Singapore. Movement Disorders, 21(1), 86-89.

Telfer, D., \& Wall, G. (1996). Linkages between tourism and food production. Annals of Tourism Research, 23(3), 635-653.

Telfer, D. J., \& Wall, G. (2000). Strengthening backward economic linkages: local food purchasing by three Indonesian hotels. Tourism Geographies, 2(4), 421-447.

Tomlinson, J. (1991). Cultural Imperialism: A Critical Introduction. Baltimore, MD: Johns Hopkins University Press.

Torres, R. (2002). Toward a better understanding of tourism and agriculture linkages in the Yucatan: tourist food consumption and preferences. Tourism Geographies, 4(3), 282-306.

Torres, R. (2003). Linkages between tourism and agriculture in Mexico. Annals of Tourism Research, 30(3), 546-566.

Torres, R., \& Skillicorn, P. (2004). Montezuma's Revenge: How Sanitation Concerns May Injure Mexico's Tourist Industry. Cornell Hotel and Restaurant Administration Quarterly, 45(2), $132-144$.

Trubek, A. B. (2008). The Taste of Place: a cultural journey into terroir. London: University of California Press. 
Tse, P., \& Crotts, J. C. (2005). Antecedents of novelty seeking: international visitors' propensity to experiment across Hong Kong's culinary traditions. Tourism Management, 26, 965-968.

Uriely, N. (2005). The tourist experience: Conceptual Developments. Annals of Tourism Research, 32(1), 199-216.

Urry, J. (2002). The Tourist Gaze (2nd ed.). London: Sage.

Vargas Llosa, M. (2001). The Culture of Liberty. Foreign Policy, 122(Jan. - Feb.), 66-71.

Wang, N. (1999). Rethinking Authenticity in Tourism Experience. Annals of Tourism Research, 26(2), 349-370.

Warde, A., \& Martens, L. (2000). Eating Out: Social Differentiation, Consumption and Pleasure. Cambridge: Cambridge University Press.

Waters, M. (2001). Globalization. London: Routledge.

Wilhelmina, Q., Joost, J., George, E., \& Guido, R. (2010). Globalization vs. localization: global food challenges and local solutions. International Journal of Consumer Studies, 34(3), 357-366.

Willging, J. (2008). Of GMOs, McDomination and Foreign Fat: Contemporary Franco-American Food Fights. French Cultural Studies, 19(2), 199-226.

Wood, R. C. (1995). The Sociology of the Meal. Edinburgh: Edinburgh University Press.

YO!Sushi. (2009). About YO! Curious to know where we came from? Retrieved Nov, 16, 2009, from http://www.yosushi.com/about 


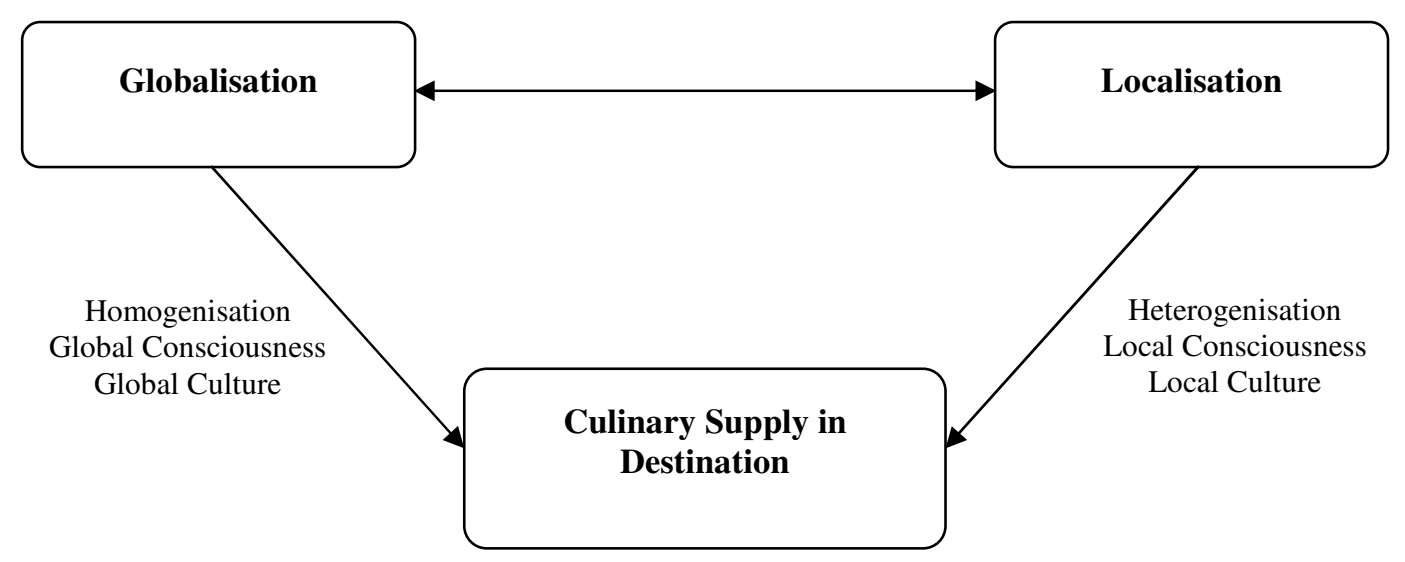

Figure 1. The influence of globalisation and localisation on culinary supply in destination 


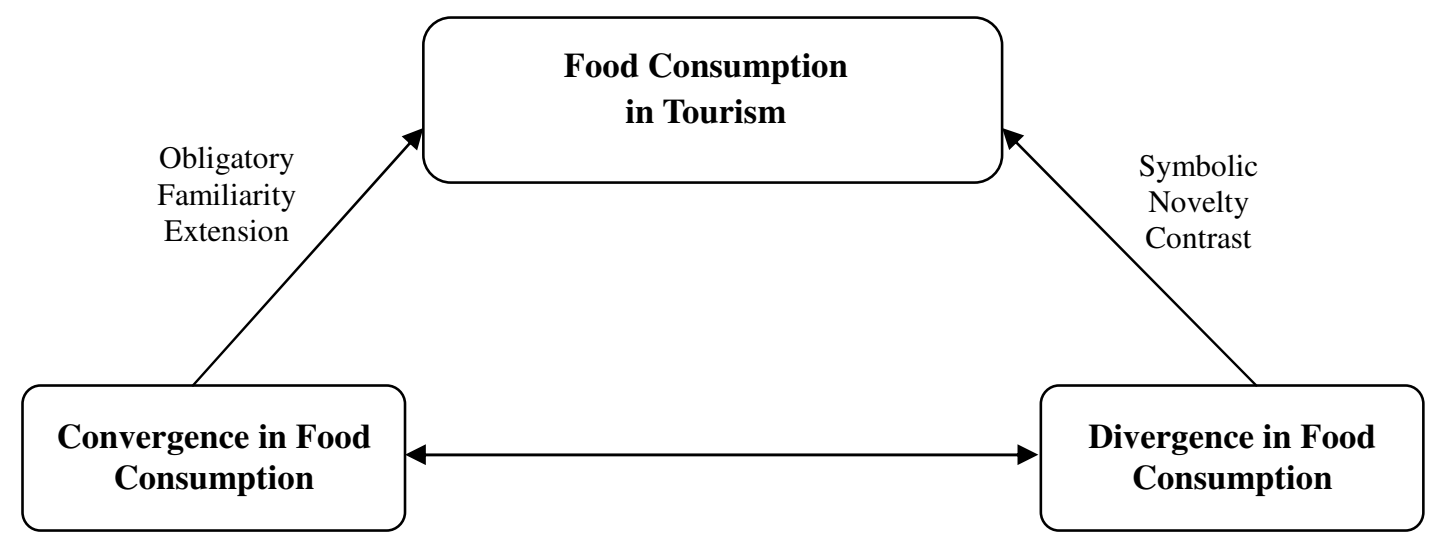

Figure 2. The influence of convergence and divergence on food consumption in tourism 


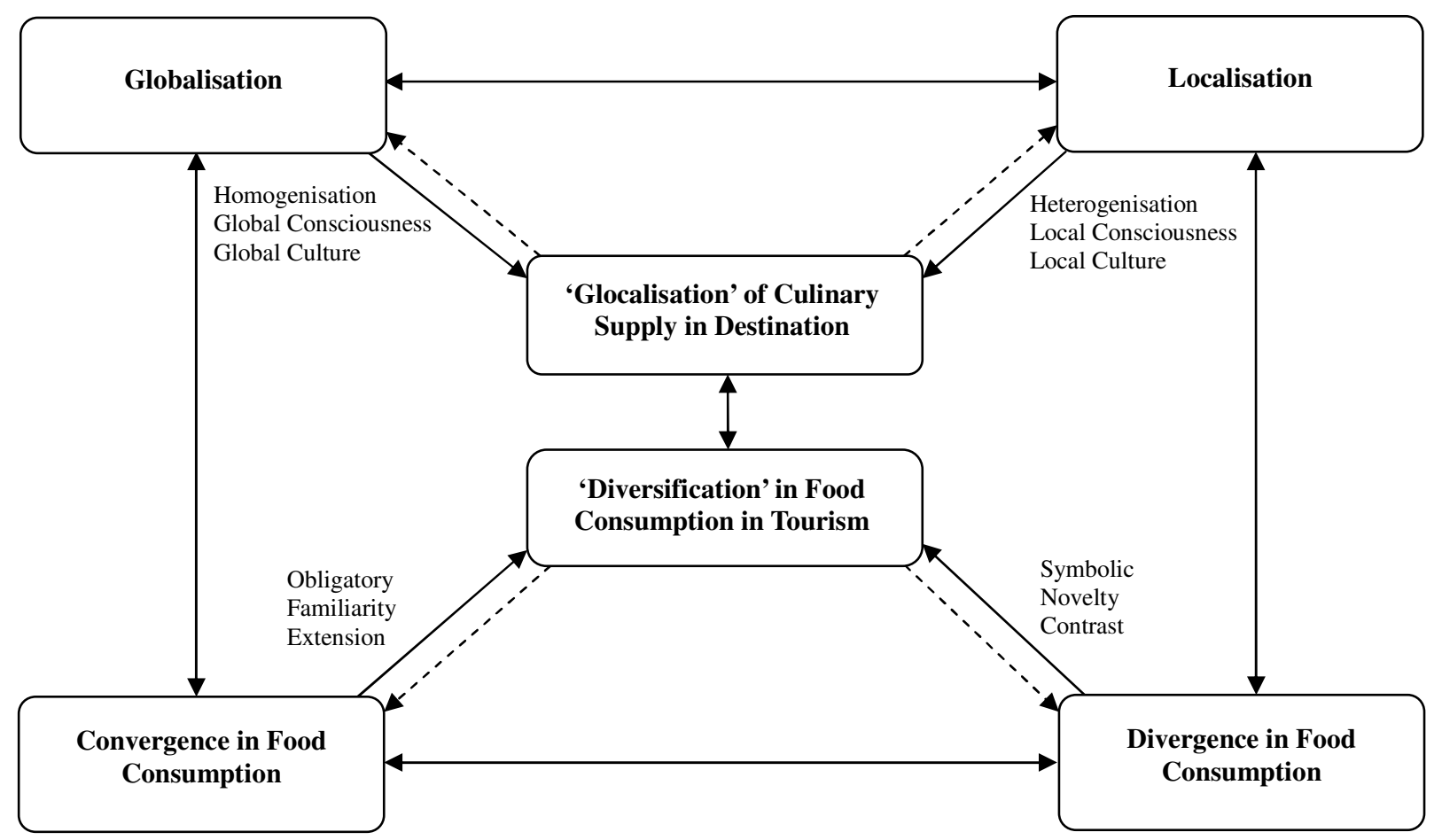

Figure 3. A model illustrating the influence of globalisation on culinary supply and food consumption in tourism 